\title{
Kinetic Energy Release in Metastable Transitions. I
}

\author{
M. Barber, Associated Electrical Industries, Manchester, England, \\ K. R. Jennings, Dept. of Chemistry, The University, Sheffield, 10, England, \\ and R. Rhodes, The Mellon Institute, Pittsburgh, Pennsylvania, U.S.A.
}

(Z. Naturforschg. 22 a, 15-19 [1967] ; received 17 October 1966)

\begin{abstract}
A method is described for detecting metastable transitions which take place with the release of kinetic energy in the field-free region between the source and electrostatic analyser of a doublefocusing mass spectrometer, and a procedure is given for evaluating the kinetic energy release. Values are given for a number of transitions and are in agreement with those obtained by other methods where comparison is possible. The variation of peak shape with accelerating voltage is ascribed to the varying efficiency with which product ions are collected.
\end{abstract}

The bombardment of polyatomic molecules with electrons frequently leads to the formation of fragment ions the kinetic energies of which are considerably in excess of thermal energies. At low accelerating voltages, these ions give rise to satellite peaks on the high mass side of normal fragment ion peaks and have been shown to arise from the decomposition of doubly-charged species in many cases ${ }^{1-5}$. Recent observaitons have shown that excited singlycharged ions may also decompose with the release of energy and so produce high kinetic energy fragment ions ${ }^{6}$.

Measurements on satellite peaks provide an estimate of the excess kinetic energy carried by the ions, and appearance potential measurements and estimates of reaction energetics have been used to postulate processes leading to high kinetic energy fragment ions. The accuracy with which such measurements can be made is not usually sufficient for an unambiguous assignment of a precursor to be made. This difficulty can be overcome by observations on metastable peaks, the positions of which on the mass scale define the decomposition reactions ${ }^{7}$ and the widths of which can be related to the kinetic energy released during the reactions ${ }^{8-10}$. The shapes of the metastable peaks vary from a broad Gaussian shape to peaks with flat or concave tops and they appear

1 A. Hustrulid, P. Kusch, and J. T. Tate, Phys. Rev. 54, 1037 [1938].

2 F. L. Mohler, V. H. Dibeler, and R. M. Reese, J. Chem. Phys. 22, 394 [1954].

3 T. Tsuchiya, J. Chem. Phys. 36, 568 [1962].

4 J. Olmstead III, K. Street, Jr., and A. S. Newton, J. Chem. Phys. 40, 2114 [1964].

5 R. Fuchs and R. Taubert, Z. Naturforschg. 19 a, 494 [1964].

${ }^{6} \mathrm{H}$. Ehrhardt and T. Tekaat, Z. Naturforschg. 19 a, 1382 [1964]. to depend on the ranges and magnitudes of kinetic energies released, the accelerating voltage and the geometry of the mass spectrometer. The release of kinetic energy calculated from the width of a metastable peak arising from a decomposition which occurs in the field-free region between the electrostatic and magnetic analysers of an A.E.I. MS9 mass spectrometer of NIER-JoHnson geometry has been shown to be in agreement with values obtained by other methods ${ }^{8,9}$. Similar observations using a CEC 21 . $110 \mathrm{~B}$ instrument of Mattauch-Herzog geometry lead to serious over-estimates of the kinetic energy released ${ }^{11}$; this has been ascribed to the transmission of ions formed by decompositions which occur in the electrostatic analyser by the wide $\beta$-stop, thereby increasing the mass range over which the ions can be collected. This effect is largely avoided in instruments in which the $\beta$-slit is relatively narrow.

This paper describes a method similar to that used by OTtinger ${ }^{12}$ in which the release of kinetic energy is derived from observations on metastable transitions which occur in the field-free region between the source and the electrostatic analyser. Differences in the geometries of the instruments used lead to somewhat different observations and methods of evaluating the kinetic energy released.

7 J. A. Hipple, Phys. Rev. 71, 594 [1947].

8 J. H. Beynon, R. A. Saunders, and A. E. Williams, Z. Naturforschg. 20 a, 180 [1965].

9 W. Higgins and K. R. Jennings, Trans. Faraday Soc. 62, 97 [1966].

10 R. Fuchs and R. Taubert, Z. Naturforschg. 20 a, 823 [1965].

11 T. W. Shannon, F. W. McLafferty, and C. R. McKinney, Chem. Comm. 1966, 478.

12 Ch. Ottinger, Phys. Letters 17, 269 [1965]. 


\section{Theory of the Method}

Consider an ion $\mathrm{m}_{1}{ }^{+}$formed in the source with zero kinetic energy and which falls through the full accelerating potential $V_{0}$ before it decomposes to give an ion $m_{2}{ }^{+}$and neutral fragment $\left(m_{1}-m_{2}\right)$ in the field-free region between the source and the electrostatic analyser, with the release of $T \mathrm{eV}$ of kinetic energy. If $v_{1}$ and $v_{2}$ are the velocities of ions $m_{1}{ }^{+}$ and $\mathrm{m}_{2}{ }^{+}$respectively, the laws of conservation of energy and momentum lead to the expression ${ }^{8}$

$$
v_{2}=v_{1}\left(1 \pm \sqrt{\mu T / V_{0} e}\right)
$$

for the maximum and minimum velocities of $\mathrm{m}_{2}{ }^{+}$ ions in the direction of the ion beam, where $e$ is the electronic charge and $\mu=\left(m_{1}-m_{2}\right) / m_{2}$. These two velocities correspond to the cases in which the whole energy is released along an axis coincident with the ion beam: in the more general case, $\mathrm{m}_{2}{ }^{+}$ions will be formed with components of velocity perpendicular to that direction of the beam (see Fig. $1 ; \alpha$ and

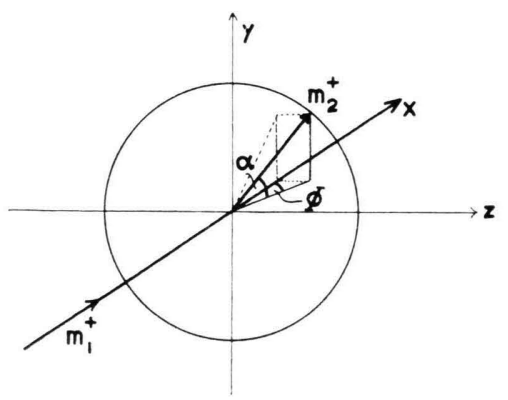

Fig. 1. Decomposition accompanied by kinetic energy release.

$\Phi$ may vary between 0 and $360^{\circ}$ ), so that their velocities in this direction will lie between the two extreme values of $v_{2}$ given by Eq. (1) ${ }^{13}$. These ions will normally be collected with reduced efficiency which will vary with operating conditions and instrumental geometry.

The range of kinetic energies of $\mathrm{m}_{2}{ }^{+}$ions in the direction of the ion beam is given by

$$
\mathrm{K} . \mathrm{E} .=\frac{1}{2} m_{2} v_{2}{ }^{2}=\frac{1}{2} m_{2} v_{1}{ }^{2}\left(1 \pm \sqrt{\mu T / V_{0} e}\right)^{2}
$$

and since

$$
v_{1}^{2}=2 V_{0} e / m_{1}
$$

$$
\text { K.E. of } m_{2}^{+}=\left(m_{2} / m_{1}\right) V_{0} e\left(1 \pm \sqrt{\mu T / V_{0} e}\right)^{2} \text {. }
$$

If the voltage $E$ across the electrostatic analyser is kept constant, thereby maintaining a constant mass scale, $\mathrm{m}_{2}{ }^{+}$ions are transmitted by the analyser only

13 M. C. Flowers, Chem. Comm. 1965, 235. if their energy after dissociation equals $V_{0} e$, where $V_{0}$ is the normal accelerating voltage appropriate to the electrostatic analyser voltage $E$. This condition is obtained by increasing the accelerating voltage to $V$ such that

$$
V_{0} e=\left(m_{2} / m_{1}\right) V e(1 \pm \sqrt{\mu T / V e})^{2}
$$

or, on rearranging

$$
\frac{V}{V_{0}}=\frac{m_{1}}{m_{2}} \cdot \frac{1}{\left(1 \pm \sqrt{\mu T / V e)^{2}}\right.} .
$$

Hence $\mathrm{m}_{2}{ }^{+}$ions are transmitted over a range of accelerating voltages, the limits of which are given by the two values of $V$ obtained by taking the positive and negative signs in Eq. (6). For the case in which $\mathrm{m}_{2}^{+}$ions are formed from $\mathrm{m}_{1}{ }^{++}$ions, an entirely analogous argument leads to

$$
\frac{V}{V_{0}}=\frac{m_{1}}{2 m_{2}} \frac{1}{(1 \pm V \mu T / 2 V e)^{2}} .
$$

If one makes the approximation

$$
(1 \pm \sqrt{\mu T / V e})^{2} \approx(1 \pm 2 \sqrt{\mu T / V e})
$$

Eq. (6) can be rearranged to give

$$
T=\frac{V}{4 \mu}\left(\frac{m_{1} V_{0}}{m_{2}} \cdot \frac{1}{V}-1\right)^{2} .
$$

When $T=0$, the accelerating voltage $V^{\prime}$ required for the transmission of $\mathrm{m}_{2}{ }^{+}$ions is given by

$$
V^{\prime}=m_{1} V_{0} / m_{2} \text {. }
$$

Putting $\Delta V=\left|V^{\prime}-V\right|, T$ is given by

$$
T=(\Delta V)^{2} / 4 \mu V .
$$

A similar argument for the process $m_{1}{ }^{++} \rightarrow m_{2}{ }^{+}$ leads to

$$
T=(\Delta V)^{2} / 2 \mu V .
$$

In practice, $\mathrm{m}_{2}{ }^{+}$ions are brought to focus in the normal manner after which the accelerating voltage is adjusted until $\mathrm{m}_{2}{ }^{+}$ions are again collected. Typical plots of the $\mathrm{m}_{2}{ }^{+}$ion intensity against accelerating voltage are shown in Fig. 2. In (a), the kinetic energy released is too small to measure, but the values of $V$ corresponding to the ends of the flat-topped region in (b) or to the two maxima in (c) and (d) are used to calculate $\Delta V$ and $T$ is calculated from Eq. (11) or (12), as is appropriate. These equations predict that the peak profiles as shown in Fig. 2 will be slightly asymmetrical about $V^{\prime}$ since $(\Delta V)^{2}$ increases as $V$ increases and so will be larger on the high voltage side of $V^{\prime}$. Experimentally, it is found that this asymmetry is very small and often lies 

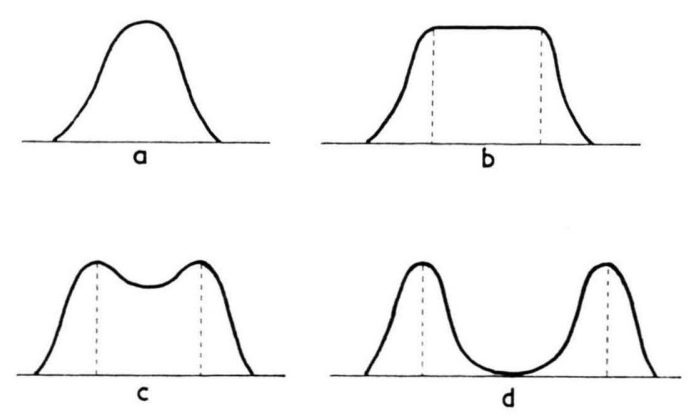

Fig. 2. Metastable Peak Shapes.

within the uncertainty in the measurement of $\Delta V$; consequently, the centre of the peak profile corresponds very closely to $V^{\prime}$ and so may be used to identify the metastable transition giving rise to $\mathrm{m}_{2}{ }^{+}$ ions.

\section{Experimental}

All experiments were carried out on an A.E.I. MS 9 mass spectrometer which was modified slightly to allow independent variation of $V$ and $E$ over wide ranges. A ten-turn precision potentiometer controlled the voltage applied to the $8 \mathrm{kV}$ stabilizing amplifier and allowed the ratio $V / V_{0}$ to be determined directly to an accuracy of better than $0.1 \%$. External batteries were used to supply a field symmetrical with respect to earth potential across the electrostatic analyser. All measurements were made using 70 volt electrons and a trap current of $90 \mu \mathrm{A}$; the source temperature was approximately $250^{\circ} \mathrm{C}$. The pressure in the source pumping line was about $2 \times 10^{-6}$ $\mathrm{mm} \mathrm{Hg}$, but the actual pressure in the ionization chamber was probably an order of magnitude greater than this. The pressure in the analyser tube was typically $2-4 \times 10^{-7} \mathrm{~mm} \mathrm{Hg}$.

In order to test the validity of the method, the method of Beynon, Saunders and Williams was used to determine the kinetic energy released in several metastable transitions; these values were then compared with values derived using the method described above.

\section{Results and Discussion}

In the mass spectrum of 2 -fluoropropene, a flattopped metastable peak in the region of $m / e=25.8$ arises from the decomposition

$$
\mathrm{C}_{3} \mathrm{H}_{4} \mathrm{~F}^{+} \rightarrow \mathrm{C}_{3} \mathrm{H}_{3}^{+}+\mathrm{HF} \text {. }
$$

Observations on the width of the peak at accelerating voltages of $1,2,4$ and $8 \mathrm{kV}$ led to a value of $0.57 \pm 0.04 \mathrm{eV}$ for the kinetic energy released, using the method of Beynon, Saunders and Williams. Observations were then made on the $V / V_{0}$ ratios required to focus $\mathrm{C}_{3} \mathrm{H}_{3}{ }^{+}$ions arising from $\mathrm{C}_{3} \mathrm{H}_{4} \mathrm{~F}^{+}$ions in the region between the source and electrostatic

\begin{tabular}{|c|c|c|c|c|c|}
\hline$E$ (volts) & $V_{\mathrm{L}} / V_{0}$ & $V_{\mathrm{H}} / V_{0}$ & $T_{\mathrm{L}}(\mathrm{eV})$ & $T_{\mathrm{H}}(\mathrm{eV})$ & $\begin{array}{c}\text { Average } \\
T(\mathrm{eV})\end{array}$ \\
\hline 67.5 & 1.471 & 1.542 & 0.53 & 0.53 & 0.53 \\
135 & 1.484 & 1.537 & 0.48 & 0.43 & 0.455 \\
202.5 & 1.492 & 1.530 & 0.35 & 0.35 & 0.35 \\
270 & 1.496 & 1.527 & 0.29 & 0.33 & 0.31 \\
337.5 & 1.498 & 1.523 & 0.28 & 0.23 & 0.255 \\
\hline
\end{tabular}

Table 1. $\mathrm{C}_{3} \mathrm{H}_{4} \mathrm{~F}^{+} \rightarrow \mathrm{C}_{3} \mathrm{H}_{3}{ }^{+}+\mathrm{HF} ; m_{1} / m_{2}=1.511 ; \mu=0.513$.

analyser: the results are given in Table 1. It is evident that all the values for $T$ are less than that determined from the width of the normal metastable peak and that the apparent value of $T$ decreases as $E$ increases. A plot of these results is shown in Fig. 3

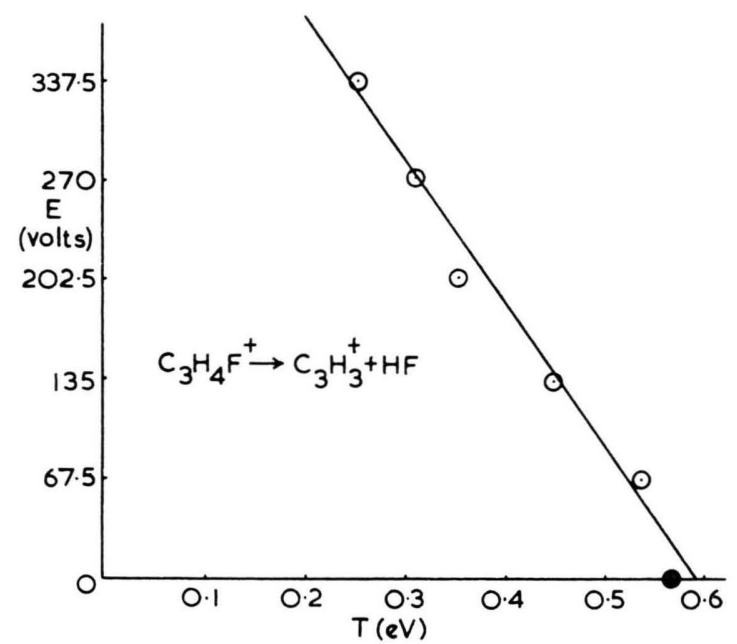

Fig. 3. Variation of Apparent Kinetic Energy Release with ESA voltage for the decomposition $\mathrm{C}_{3} \mathrm{H}_{4} \mathrm{~F}^{+} \rightarrow \mathrm{C}_{3} \mathrm{H}_{3}^{+}+\mathrm{HF}$ in the mass spectrum of 2 -fluoropropene.

and it can be seen that the value of the kinetic energy release obtained by extrapolating to zero electrostatic analyser voltage is $0.59 \mathrm{eV}$, in good agreement with the value reported above.

Similar observations were made on the $\mathrm{C}_{5} \mathrm{H}_{3}{ }^{+}$ion formed in the reaction

$$
\mathrm{C}_{6} \mathrm{H}_{6}{ }^{++} \rightarrow \mathrm{C}_{5} \mathrm{H}_{3}{ }^{+}+\mathrm{CH}_{3}{ }^{+}
$$


in the mass spectrum of benzene, in which $2.67 \mathrm{eV}$ of kinetic energy are released. The results are summarized in Fig. 4 and once again, a similar relationship is observed between $T$ and $E$ and the value of $T$ obtained by extrapolating to $E=0$ is in good agreement with values obtained by other methods. Many

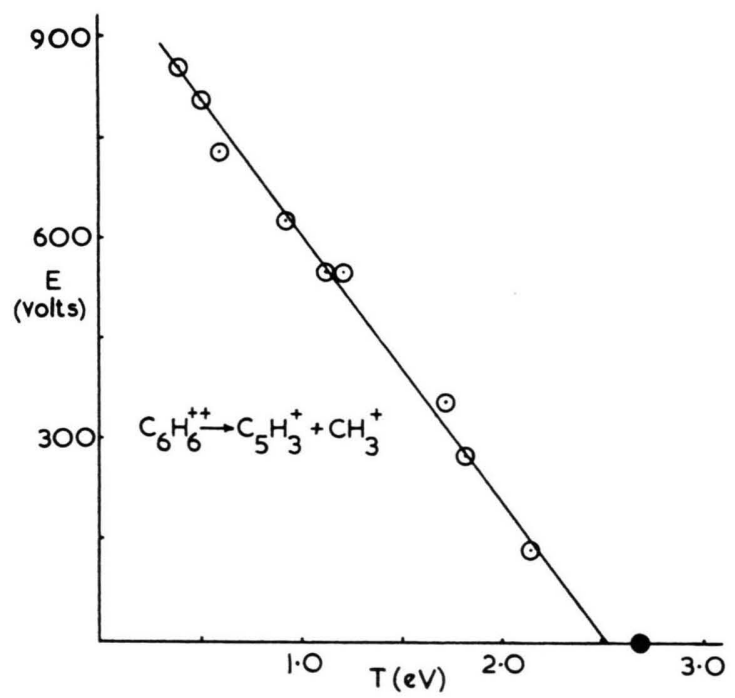

Fig. 4. Variation of Apparent Kinetic Energy Release with ESA voltage for the reaction $\mathrm{C}_{6} \mathrm{H}_{6}{ }^{++} \rightarrow \mathrm{C}_{5} \mathrm{H}_{3}^{+}+\mathrm{CH}_{3}{ }^{+}$(based on observations on the peak given by the $\mathrm{C}_{5} \mathrm{H}_{3}{ }^{+}$ion) in the mass spectrum of benzene.

other metastable transitions in which kinetic energy is released have now been investigated by this method and a similar trend is observed in each case. For decompositions giving strong signals, the true kinetic energy release is obtained by extrapolating to $E=0$, and where comparison with other methods is possible, the values are in good agreement. Some of these decompositions are listed in Table 2.

The theoretical justification for this procedure can be seen by considering more carefully the simplifying assumptions made in the derivation of Eqs. (6) and (7). These equations are strictly applicable only if no ions are collected for which $\alpha$ and $\Phi$ have values other than $0^{\circ}$ and $180^{\circ}$. Owing to the finite widths of slits in an instrument, this condition is never realized in practice but is most nearly fulfilled when light ions carrying considerable excess kinetic energy are observed at low accelerating voltages (and hence at low electrostatic analyser voltages). For example, the $\mathrm{CH}_{3}{ }^{+}$ions formed in reaction (14) carry $2.16 \mathrm{eV}$ compared with the $0.51 \mathrm{eV}$ carried by the $\mathrm{C}_{5} \mathrm{H}_{3}{ }^{+}$ions ${ }^{9}$, and with $E=135$ volts, observa-

\begin{tabular}{|c|c|c|}
\hline Compound & Metastable Transition & $\begin{array}{c}T \mathrm{eV} \\
( \pm 10 \%)\end{array}$ \\
\hline $\begin{array}{l}\text { n-butane, } \\
\text { butene-1, } \\
\text { cis-butene-2, } \\
\text { butadiene } \\
\text { cyclopropane, } \\
\text { propylene }\end{array}$ & $\mathrm{C}_{3} \mathrm{H}_{5}{ }^{++} \rightarrow \mathrm{C}_{2} \mathrm{H}_{2}^{+}+\mathrm{CH}_{3}^{+}$ & 3.0 \\
\hline pyridine & $\mathrm{C}_{5} \mathrm{H}_{5} \mathrm{~N}^{++} \rightarrow 5 \mathrm{l}^{+}+28^{+}$ & 2.6 \\
\hline fluorobenzene & $\mathrm{C}_{6} \mathrm{H}_{5} \mathrm{~F}^{++} \rightarrow \mathrm{C}_{5} \mathrm{H}_{3}^{+}+\mathrm{CH}_{2} \mathrm{~F}^{+}$ & 3.2 \\
\hline toluene & $\mathrm{C}_{7} \mathrm{H}_{7}++\rightarrow \mathrm{C}_{4} \mathrm{H}^{+}+\mathrm{C}_{3} \mathrm{H}_{3}^{+}$ & 3.5 \\
\hline & $\rightarrow \mathrm{C}_{5} \mathrm{H}_{5}^{+}+\mathrm{C}_{2} \mathrm{H}_{2}{ }^{+}$ & 2.8 \\
\hline & $\mathrm{C}_{7} \mathrm{H}_{6}{ }^{++} \rightarrow \mathrm{C}_{5} \mathrm{H}^{+}+\mathrm{C}_{2} \mathrm{H}_{3}^{+}$ & 2.5 \\
\hline & $\mathrm{C}_{7} \mathrm{H}_{2}^{++} \rightarrow \mathrm{C}_{4} \mathrm{H}^{+}+\mathrm{C}_{3} \mathrm{H}^{+}$ & - \\
\hline $\begin{array}{l}\text { vinyl fluoride } \\
1,1 \text { difluorethane }\end{array}$ & $\begin{aligned} \mathrm{C}_{2} \mathrm{H}_{3} \mathrm{~F}^{+} & \rightarrow \mathrm{C}_{2} \mathrm{H}^{+}+\mathrm{HF} \\
\mathrm{CHF}_{2}+ & \rightarrow \mathrm{CF}^{+}+\mathrm{HF}\end{aligned}$ & $\begin{array}{c}0.68 \\
-\end{array}$ \\
\hline 2-fluoroethanol & $\mathrm{CH}_{3} \mathrm{O}^{+} \rightarrow \mathrm{CHO}^{+}+\mathrm{H}_{2}$ & - \\
\hline $\begin{array}{l}\text { propargyl } \\
\text { bromide }\end{array}$ & $\mathrm{C}_{3} \mathrm{H}_{3} \mathrm{Br}^{+} \rightarrow \mathrm{C}_{3} \mathrm{H}_{3}^{+}+\mathrm{Br}$ & - \\
\hline
\end{tabular}

Table 2.

tions on the $\mathrm{CH}_{3}{ }^{+}$ions lead to a value of $T=2.50$ $\mathrm{eV}$, very little below the accepted value. This may be compared with $T=2.10 \mathrm{eV}$ calculated from observations on the $\mathrm{C}_{5} \mathrm{H}_{3}{ }^{+}$ions at the same electrostatic analyser voltage. At higher voltages, the kinetic energy released in the decomposition becomes of decreasing significance when compared with the kinetic energy of the ions in the direction of the ion beam. Consequently, fewer ions are lost, especially if the ion is relatively heavy and carries only a small fraction of the energy released in the decomposition reaction. The effect of collecting ions which possess velocity components perpendicular to the direction of the ion beam is to cause the intensity maxima to move slightly towards the centre of the peak profile and for the intensity of the centre portion to increase as shown in Fig. 5. This reduction in separation of

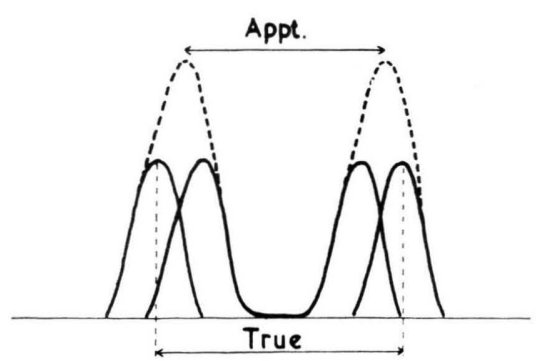

Fig. 5. Apparent reduction in peak width arising from the collection of ions for which $\alpha$ and $\varphi$ are non-zero.

the two maxima leads to a lower value of $\Delta V$ and hence to a lower value of $T$ and it is most marked at high accelerating voltages where the greatest frac- 
tion of ions is collected. In the limit, the two maxima coalesce so as to produce a broad Gaussian-shaped peak. An example of this behaviour is found in the mass spectrum of fluorobenzene in which the reaction

$$
\mathrm{C}_{6} \mathrm{H}_{5} \mathrm{~F}^{+} \rightarrow \mathrm{C}_{6} \mathrm{H}_{4}^{+}+\mathrm{HF}
$$

occurs with the release of a small amount of kinetic energy, and gives rise to a small flat-topped metastable peak at $m / e=60.2$. When this metastable transition is observed in the region between the source and electrostatic analyser, the peak profile resembles that shown in Fig. 2(b) at low accelerating voltages, but with $E=405$ volts, the shape resembles that shown in Fig. 2(a). Under these conditions, the flat-topped region is too small to measure accurately and becomes a function of the slit widths. At lower accelerating voltages, the precise limits of the flat-topped region appear to depend on the sensitivity at which the peak profile is observed,

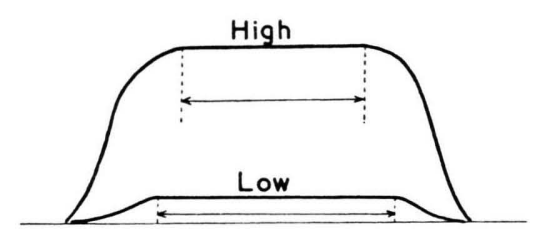

Fig. 6. Apparent variation of flat-topped region with sensitivity. as is shown in Fig. 6. Observations on reaction (15) have led to very approximate values of $1.5 \mathrm{eV}$ (high sensitivity) and $2.5 \mathrm{eV}$ (low sensitivity) for the kinetic energy released, the lower value probably being more nearly correct. Where the voltage range of the flat-topped region is relatively small as in this case, owing to the heavy ion carrying only a small fraction of the kinetic energy released, values of $T$ derived from flat-topped peaks are likely to be subject to considerable error.

The sample of results listed in Table 2 confirms the suggestion that metastable transitions in which kinetic energy is released are quite widespread, and that the doubly-charged species giving the high kinetic energy fragment ions are frequently themselves fragment ions rather than molecular ions.

\section{Conclusion}

The method described is very sensitive in detecting metastable transitions in which kinetic energy is released and in favourable cases, a reasonably accurate estimate of this energy can be made. A quantitative account of metastable peak profiles will be published elsewhere, but the general features can be explained qualitatively in terms of the fraction of ions after dissociation which reach the collector. 